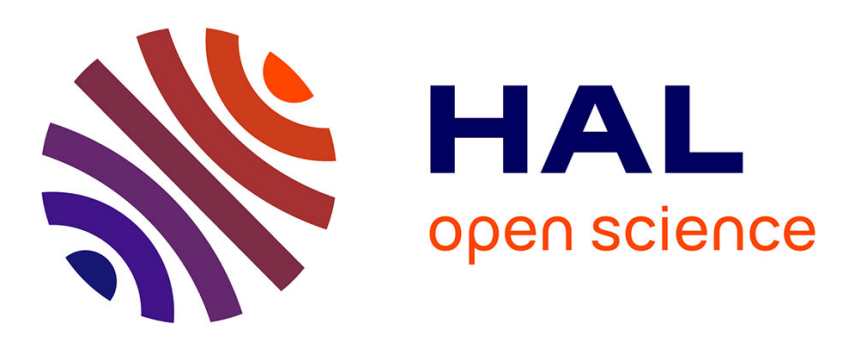

\title{
Design and Optimization of Magnetic Gears with Arrangement and Mechanical Constraints for Wind Turbine Applications
}

Melaine Desvaux, Roman Le Goff Latimier, Bernard Multon, Hamid Ben Ahmed, Stéphane Sire

\section{To cite this version:}

Melaine Desvaux, Roman Le Goff Latimier, Bernard Multon, Hamid Ben Ahmed, Stéphane Sire. Design and Optimization of Magnetic Gears with Arrangement and Mechanical Constraints for Wind Turbine Applications. EVER'16, Apr 2016, Monaco, Monaco. hal-01312302

\section{HAL Id: hal-01312302 https://hal.science/hal-01312302}

Submitted on 5 May 2016

HAL is a multi-disciplinary open access archive for the deposit and dissemination of scientific research documents, whether they are published or not. The documents may come from teaching and research institutions in France or abroad, or from public or private research centers.
L'archive ouverte pluridisciplinaire HAL, est destinée au dépôt et à la diffusion de documents scientifiques de niveau recherche, publiés ou non, émanant des établissements d'enseignement et de recherche français ou étrangers, des laboratoires publics ou privés. 


\section{Design and Optimization of Magnetic Gears with Arrangement and Mechanical Constraints for Wind Turbine Applications}

\author{
Melaine Desvaux, \\ Roman Le Goff Latimier, \\ Bernard Multon and Hamid Ben Ahmed \\ SATIE, ENS Rennes \\ Univ. Bretagne Loire, CNRS \\ 35170 Bruz, France \\ Email: melaine.desvaux@ens-rennes.fr
}

\author{
Stéphane Sire \\ Univ. Bretagne Occidentale \\ FRE CNRS 3744, IRDL \\ 29238 Brest, France
}

Email: stephane.sire@univ-brest.fr

\begin{abstract}
This article focuses on the design and optimization of magnetic and mechanical (structural) parts of magnetic gears for wind turbine applications. In particular, this design takes into account the structural aspects of magnetic gears as well as the system's mechanical constraints (deformation and stress). Geometric parameters have been optimized in order to minimize the material costs for a $3.9 \mathrm{MW}, 15 \mathrm{rpm}$ wind turbine. This optimization strategy includes both magnetostatic and mechanical stationary finite element analyses. Optimization results underscore the necessity to take mechanical constraints into account, especially for the fixed ferromagnetic pole pieces.
\end{abstract}

Keywords-magnetic gears; arrangement; mechanical constraints; optimization; finite element analysis; wind turbine.

\section{INTRODUCTION}

For wind turbine applications, mechanical gearboxes are frequently used in indirect drive (Fig. 1a); this design yields a lower investment cost and less weight compared to direct drive designs (Fig. 1b). However, the failures of mechanical gearboxes and their induced production interruptions, which increase operating costs, are more frequently observed with indirect drive designs [1].

An effective intermediate solution calls for using a faster (and lighter weight) generator than in typical indirect drive designs and combining it with magnetic gears (Fig. 1c) to obtain an indirect magnetic drive. The most attractive topology of magnetic gears (Fig. 2) was proposed by [2] in the early 2000's and applied in various studies [3-5]. This magnetic gear topology offers the potential for high performance and the promise of greater competitiveness compared to mechanical solutions [6], even for high-torque applications (e.g. an offshore wind turbine) [7-10]. In this article, only the case of fixed ferromagnetic pole pieces will be studied.

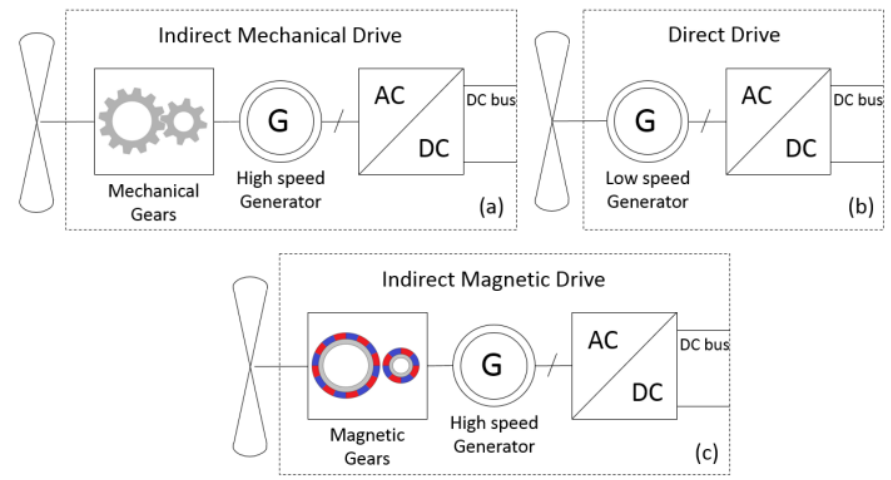

Fig. 1: Wind power conversion chains (a) indirect mechanical drive, (b) direct drive, and (c) indirect magnetic drive

Magnetic gears are composed of three rings, i.e.:

- A high-speed rotor ring with $\mathrm{p}_{\mathrm{h}}$ pole pairs of permanent magnets and a ferromagnetic yoke,

- A relative low-speed rotor ring with $p_{1}$ pole pairs of permanent magnets and a ferromagnetic yoke,

- A fixed ferromagnetic ring with $\mathrm{n}_{\mathrm{s}}$ pole pieces interposed between the two rotors (an example is given in Figure 2 with $p_{h}=2, p_{1}=7$ and $n_{s}=9$ ). 
Each rotor generates a magneto motive wave in the airgaps. Ferromagnetic pole pieces are intended to modulate the field of the two rotors by means of a common field harmonic, resulting in a magnetic torque with an average value different from zero.

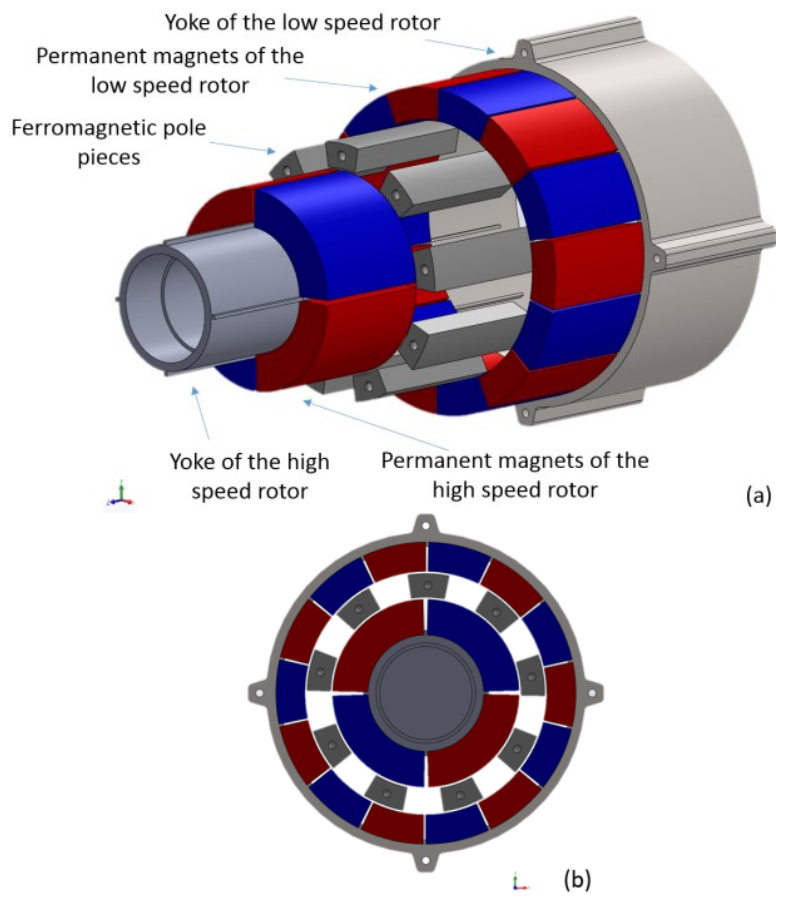

Fig. 2: Magnetic part of the magnetic gears (a) in a close-up drawing, (b) in a side view drawing (in this example, $\mathrm{p}_{\mathrm{h}}=2, \mathrm{p}_{\mathrm{l}}=7, \mathrm{n}_{\mathrm{s}}=9$ )

To be successful, the three rings must respect Equation (1) by complying with the gear ratio given in (2) [3]. According to the studied configuration (i.e. fixed ferromagnetic pole pieces), the rotational speeds of the two rotors are opposite (as the gear ratio is negative).

$$
\begin{gathered}
p_{h}+p_{l}=n_{S} \\
G_{r}=-p_{l} / p_{h}
\end{gathered}
$$

Magnetic gears have already been optimized in $[11,12]$. This optimization step however merely focused on the system's magnetic parts without taking into account its structural parts, which constitute a large share of the total weight. In earlier optimization work, neither mechanical nor arrangement constraints were considered.

The present paper will examine the magnetic gear design and optimization. The major contribution of this work pertains to the overall design and optimization aspects (magnetic and mechanical) of the magnetic gear by including both arrangement and mechanical (deformation and stress) constraints.

\section{PRELIMINARY ARRANGEMENT AND STRUCTURAL GEOMETRY OF THE MAGNETIC GEAR}

The first step of our design approach entailed defining a arrangement of magnetic gear structural parts and magnetic parts. This arrangement must respect mechanical mounting constraints while being adapted to a mechanical wind turbine dimension for the various magnetic gear parts (namely high-speed rotor, low-speed rotor and fixed ferromagnetic pole pieces). The selected arrangement is presented in Figure 3 (for this depiction, the dimensions do not correspond to a high torque application).

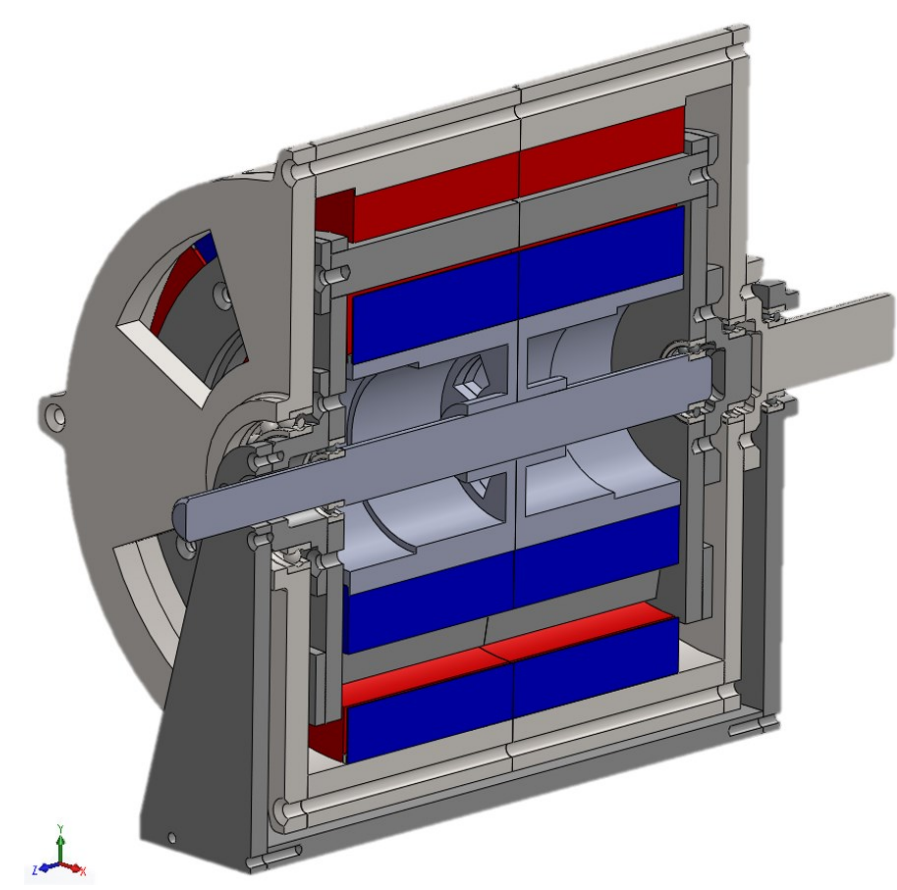

Fig. 3: Magnetic gear arrangement in an axial cross-section

The geometry of the various magnetic gear parts was then defined, as shown in Figure 4. From a geometric point of view, the definitions of low-speed rotor and fixed ferromagnetic pole pieces were very similar since end bells were used in their composition. In contrast, the high-speed rotor geometry was quite different given that permanent magnets were placed outside the structural part. A material cost minimization of the three structural parts is obtained by reducing part weight through the use of holes.

The most sophisticated mechanical design was observed for the fixed ferromagnetic pole pieces. Since this part is located between the high-speed rotor and the low-speed rotor, any radial reinforcement is in fact impossible. Moreover, the pole pieces play an important role during magnetic and mechanical operations. 


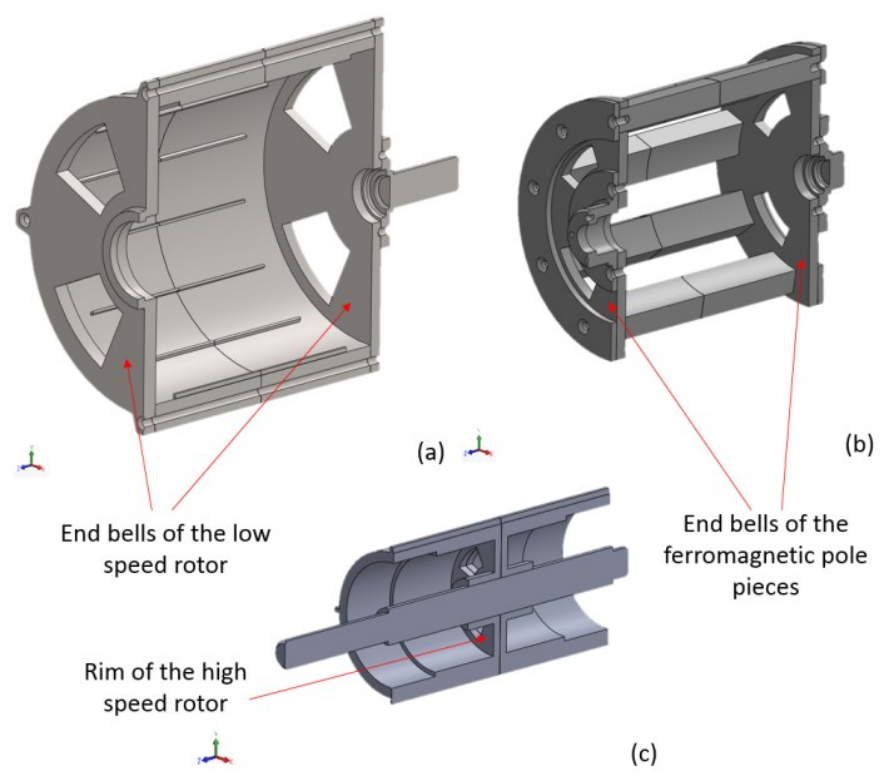

Fig. 4: Structural parts of (a) low-speed rotor, (b) fixed ferromagnetic pole pieces, and (c) high-speed rotor

\section{DEFINITION OF MAGNETIC GEAR GEOMETRIC PARAMETERS FOR OPTIMIZATION PURPOSES}

From this structural geometry and arrangement, it became possible to define the most important geometric parameters. For various sets of parameters, the magnetic gear could be evaluated with different finite element analyses in order to evaluate the range of constraints and loads that will be developed in the next section. Parameters were then defined for both the magnetic finite element analysis and mechanical finite element analysis.

Six geometric parameters were defined for the magnetic finite element analysis (Fig. 5): yoke radial thickness of the two rotors $\left(\mathrm{e}_{\text {yoke_h }}, \mathrm{e}_{\mathrm{yoke} \_}\right)$; radial thickness of the permanent magnet for both rotors $\left(\mathrm{e}_{\mathrm{pm} \_} \mathrm{h}, \mathrm{e}_{\mathrm{pm} \_}\right)$; radial thickness of the ferromagnetic pole pieces $\left(\mathrm{e}_{\mathrm{s}}\right)$; and number of high-speed rotor pole pairs $\mathrm{p}_{\mathrm{h}}$ which imposed $\mathrm{p}_{\mathrm{l}}$ and $\mathrm{n}_{\mathrm{s}}$ with (1) and (2). Among these six parameters, four are also used in the mechanical finite element analysis $\left(\mathrm{p}_{\mathrm{h}}, \mathrm{e}_{\text {yoke_ }} \mathrm{h}, \mathrm{e}_{\mathrm{s}}, \mathrm{e}_{\text {yoke_ }}\right)$. Moreover, the yoke of the two rotors and the ferromagnetic pole pieces all have a dual magnetic and mechanical purpose and represent the magneto-mechanical parts of the magnetic gears.

Twelve more geometric parameters were defined for the mechanical finite element analysis relative to the three structural parts, i.e.: inner radius of the hole and angular ratio between hole and arms (Fig. 6); end bell thickness and yoke reinforcement thickness for the low-speed rotor; end bell thickness for the fixed ferromagnetic pole pieces; yoke reinforcement thickness and length for the high-speed rotor; and rim thickness for the high-speed rotor (Fig. 7).

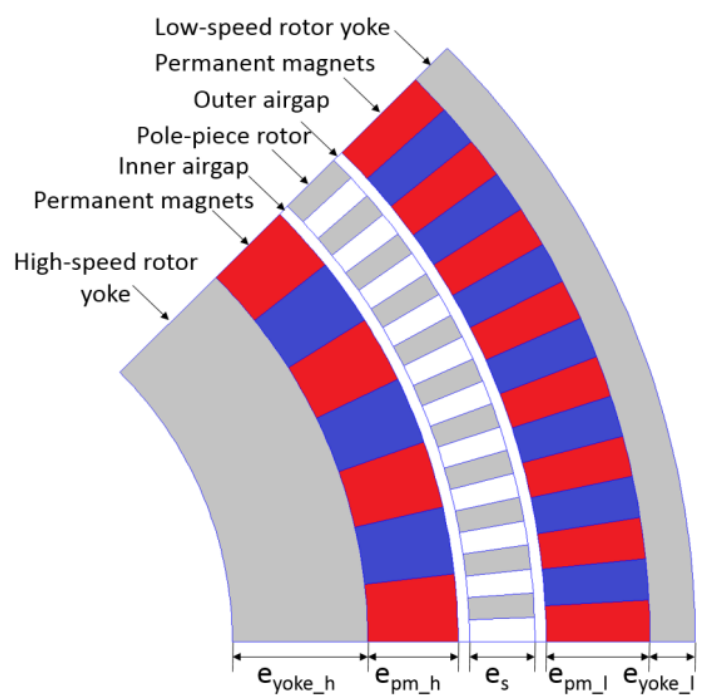

Fig. 5: Geometric parameters for a 2D magnetic finite element analysis
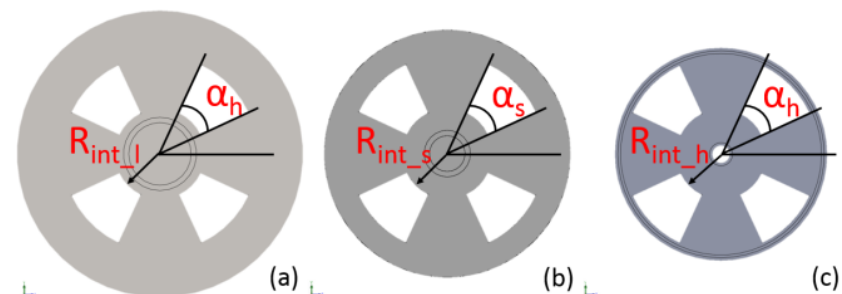

(b)

(c)

Fig. 6: Inner radius of the hole and angular ratio between hole and arm, as parameters input into the mechanical finite element analysis for (a) low speed rotor, (b) fixed ferromagnetic pole pieces, and (c) high speed rotor

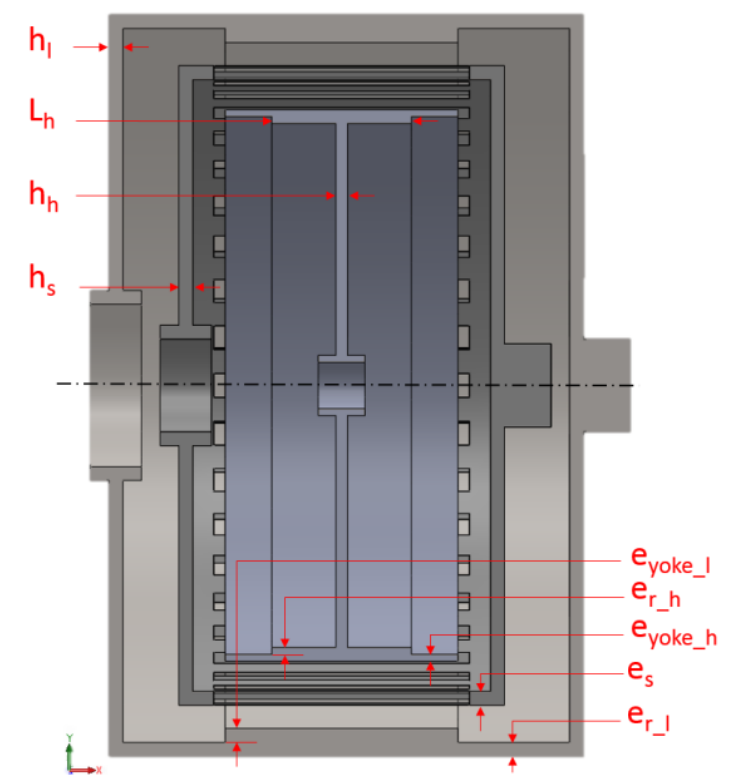

Fig. 7: Geometric parameters for a mechanical finite element analysis, including the structural parts of the: low-speed rotor, the inside highspeed rotor, and the fixed ferromagnetic pole pieces 


\section{FINITE ELEMENT ANALYSIS}

\section{A. Magnetic finite element analysis}

The magnetic finite element analysis is conducted with a 2D magnetostatic model using just the magnetic parts of the magnetic gears [12]. As regards the lower limit of the high-speed rotor and the outer bound of the low-speed rotor, Dirichlet conditions were imposed for the flux line. To undertake this analysis, three materials were used, each featuring different magnetic properties: a permanent magnet with radial induction and a linear magnetic behavior, pure iron with a nonlinear magnetic behavior, and air.

To reduce computation time and in recognition of the number of magnetically identical sections $\mathrm{S}$, as described in [10], only a small portion of the magnetic gears is actually studied. A magnetically identical section must exhibit a relationship between the numbers of pole pairs and the number of ferromagnetic pole pieces. The symmetrical nature of the magnetic system considerably limits the computation time required for the magnetic finite element analysis.

With this model, it was possible to determine the flux density everywhere in the magnetic parts of the magnetic gears for various parameter pairs. It was also possible to evaluate both the maximum gear torque per linear meter and the radial force per linear meter for all parameter pairs.

\section{B. Mechanical finite element analysis}

\section{1) Load analysis}

In assuming that the various structural parts should be capable of supporting the magnetic (and other physical) loads, a range of loads are evaluated. It was decided at first to control the influence of four distinct loads, as described in [13] for the three structural parts:

- magnetic torque,

- radial magnetic force,

- gravitational pull,

- centripetal force.

Given the dimensions of the magnetic gear presented in Table 2 (the gear diameter was greater than its length) and the rotational speed of the wind turbine inside which the system needs to be installed, the impacts of gravitational pull and centripetal force seem negligible compared to the impacts of magnetic torque and radial magnetic force. Hence, only the magnetic torque and radial magnetic force will be evaluated in controlling the mechanical efficiency of the structural parts.

\section{2) Mechanical constraints}

Magnetic torque and radial force generate torsion and bending deformations in all three structural parts, along with stress concentrations that can damage the various magnetic gear parts. It was necessary therefore to assign mechanical constraints when evaluating the mechanical efficiency of structural parts. It was decided to evaluate mechanical stresses using the Von Mises yield criterion, which takes the various stress tensor terms into account [14]. Revised deformation limits were proposed with respect to overall system dimensions in [15]. These limits were specifically adapted to the magnetic gears:

- Radial deflection due to the radial magnetic force must be less than $10 \%$ of the airgap;

- The relative twist due to magnetic torque must be less than $0.01^{\circ}$;

- The Von Mises stress due to magnetic torque and radial force must be less than the yield stress of the material $\left(\sigma_{\mathrm{y}}\right)$, with a safety factor as described in (3).

$$
\sigma \text { Von Mises } \leq 2 . \sigma_{y} / 3
$$

\section{3) Mechanical models}

To evaluate the mechanical constraints with these two distinct loads (magnetic torque and radial force), mechanical models needed to be established for the three structural parts, in addition to boundaries for the fixed constraints and load conditions.

An analysis of the two loads was not carried out in the same simulation given that magnetic torque only generates torsional deflection and mechanical stress; moreover, the magnetic radial force generates radial deflection and mechanical stress.

Magnetic torque and radial force can be applied with the same boundaries in the two simulations. The fixed constraint boundaries were the same in both simulations. The fixed constraint boundaries are presented in red and boundary loads in blue for the various structural parts in Figure 8. 


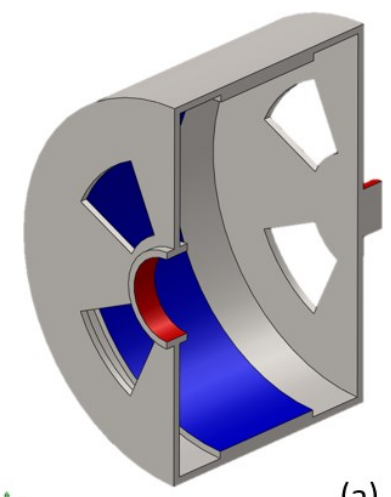

(a)

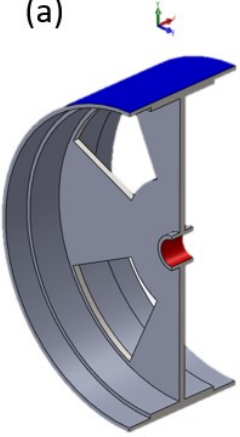

(c)

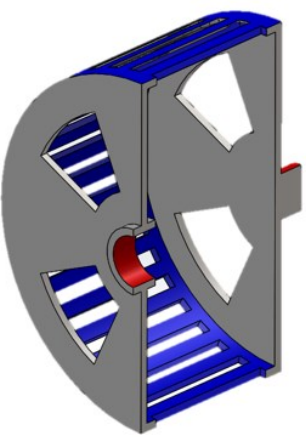

(b)
The objective function $\mathrm{C}$ of the optimization is therefore the sum of the costs of the three materials, as given in (4):

$$
C=C_{P M} . \rho_{P M} . V_{P M}+C_{F S} . \rho_{F S} . V_{F S}+C_{S S} . \rho_{S S} . V_{S S}
$$

where $V_{P M}, V_{F S}$ and $V_{S S}$ are the respective volumes, in $\mathrm{m}^{3}$, of the various materials and depend on the geometric optimization parameters.

\section{B. Magnetic gear dimensions and range of parameter values}

The geometric parameters of the magnetic gear have been optimized in order to minimize the total material costs of a $3.9 \mathrm{MW}, 15 \mathrm{rpm}$ wind turbine. The magnetic gear dimensions were imposed by the wind turbine, whereas other dimensions, like the gear ratio and airgap length, were dictated by assembly feasibility constraints introduced by the industrial partner. All fixed magnetic gear dimensions are listed in Table 2.

\section{TABLE 2: DATA AND CONSTRAINTS ASSOCIATED WITH THE} MAGNETIC GEAR

Fig. 8: Fixed constraint boundaries shown in red and load boundaries in blue for (a) low speed rotor, (b) fixed ferromagnetic pole pieces, and (c) high speed rotor

\section{OPTIMIZATION OF THE MAGNETIC GEAR}

\section{A. Objective function}

The objective function of this optimization step is to minimize the overall material cost of the magnetic and structural parts of the magnetic gear. All structural parts are composed of a single material, while the magnetic parts of the gear contain two materials: permanent magnets, and a ferromagnetic steel. The properties of these materials are indicated in Table 1.

TABLE 1: MATERIAL, PHYSICAL AND ECONOMIC PROPERTIES

\begin{tabular}{|c|c|c|}
\hline Symbol & Quantity & Value \\
\hline $\mathrm{N} 38 \mathrm{SH}$ & Permanent magnet designation & - \\
\hline $\mathrm{B}_{\mathrm{r}}$ & Remanence of the magnets & $1.26 \mathrm{~T}$ \\
\hline$\rho_{\mathrm{PM}}$ & Density of permanent magnets & $7,500 \mathrm{~kg} / \mathrm{m}^{3}$ \\
\hline $\mathrm{CPM}_{\mathrm{PM}}$ & Permanent magnet material cost & $€ 66 / \mathrm{kg}$ \\
\hline $\mathrm{M} 400-65$ & Ferromagnetic steel designation & - \\
\hline$\rho_{\mathrm{FS}}$ & Density of the ferromagnetic steel & $7,800 \mathrm{~kg} / \mathrm{m}^{3}$ \\
\hline $\mathrm{C}_{\mathrm{FS}}$ & Ferromagnetic steel material cost & $€ 2 / \mathrm{kg}$ \\
\hline$\rho_{\mathrm{SS}}$ & Structural steel density & $7,800 \mathrm{~kg} / \mathrm{m}^{3}$ \\
\hline $\mathrm{CSS}_{\mathrm{ES}}$ & Structural steel material cost & $€ 1 / \mathrm{kg}$ \\
\hline $\mathrm{E}$ & $\begin{array}{c}\text { Young's modulus of the structural and } \\
\text { ferromagnetic steel }\end{array}$ & $210 \mathrm{GPa}$ \\
\hline$\sigma_{\mathrm{y}}$ & $\begin{array}{c}\text { Yield stress of the structural and } \\
\text { ferromagnetic steel }\end{array}$ & $400 \mathrm{MPa}$ \\
\hline
\end{tabular}

\begin{tabular}{|c|c|c|}
\hline Symbol & Quantity & Value \\
\hline $\mathrm{P}_{\text {nom }}$ & Nominal power & $3.9 \mathrm{MW}$ \\
\hline $\mathrm{N}_{\text {nom }}$ & Speed of the high-speed rotor & $15 \mathrm{rpm}$ \\
\hline $\mathrm{T}_{\text {nom }}$ & Nominal torque & $2.5 \mathrm{MNm}$ \\
\hline $\mathrm{T}_{\mathrm{G}}$ & Maximum gear torque & $2.7 \mathrm{MNm}$ \\
\hline $\mathrm{G}_{\mathrm{r}}$ & Gear ratio & 6.5 \\
\hline $\mathrm{D}$ & $\begin{array}{c}\text { External diameter of the magnetic } \\
\text { parts }\end{array}$ & $3.8 \mathrm{~m}$ \\
\hline$\delta_{\mathrm{h}}$ & Length of inner airgap & $5 \mathrm{~mm}$ \\
\hline$\delta_{\mathrm{l}}$ & Length of outer airgap & $5 \mathrm{~mm}$ \\
\hline
\end{tabular}

In accordance with the second part, the geometric parameters comprise 6 parameters for the magnetic study and 16 parameters for the mechanical study of the three structural parts (whereas 4 parameters are commonly associated with a magnetic study). For the optimization step, it was necessary to define a value range for all geometric parameters (see Table 3 below). 
TABLE 3: VALUE RANGE OF THE GEOMETRIC PARAMETERS

\begin{tabular}{|c|c|c|c|}
\hline Symbol & Quantity & $\begin{array}{l}\text { Minimum } \\
\text { value }\end{array}$ & $\begin{array}{l}\text { Maximum } \\
\text { value }\end{array}$ \\
\hline $\mathrm{p}_{\mathrm{h}}$ & High-speed rotor pole pairs & 16 & 40 \\
\hline eyoke_h & $\begin{array}{l}\text { Radial thickness of the high- } \\
\text { speed rotor yoke }\end{array}$ & $30 \mathrm{~mm}$ & $200 \mathrm{~mm}$ \\
\hline eyoke_1 & $\begin{array}{l}\text { Radial thickness of the low- } \\
\text { speed rotor yoke }\end{array}$ & $30 \mathrm{~mm}$ & $150 \mathrm{~mm}$ \\
\hline $\mathrm{e}_{\mathrm{pm} \_\mathrm{h}}$ & $\begin{array}{l}\text { Radial thickness of high-speed } \\
\text { rotor permanent magnets }\end{array}$ & $5 \mathrm{~mm}$ & $60 \mathrm{~mm}$ \\
\hline $\mathrm{e}_{\mathrm{pm} \_} 1$ & $\begin{array}{l}\text { Radial thickness of low-speed } \\
\text { rotor permanent magnets }\end{array}$ & $5 \mathrm{~mm}$ & $60 \mathrm{~mm}$ \\
\hline $\mathrm{e}_{\mathrm{s}}$ & $\begin{array}{c}\text { Radial thickness of } \\
\text { ferromagnetic pole pieces }\end{array}$ & $30 \mathrm{~mm}$ & $200 \mathrm{~mm}$ \\
\hline Rint_h & $\begin{array}{l}\text { Inner radius of high-speed } \\
\text { rotor holes }\end{array}$ & $200 \mathrm{~mm}$ & $600 \mathrm{~mm}$ \\
\hline Rint_1 & $\begin{array}{c}\text { Inner radius of low-speed } \\
\text { rotor holes }\end{array}$ & $300 \mathrm{~mm}$ & $600 \mathrm{~mm}$ \\
\hline $\mathrm{R}_{\text {int_s }}$ & $\begin{array}{c}\text { Inner radius of ferromagnetic } \\
\text { pole pieces }\end{array}$ & $200 \mathrm{~mm}$ & $600 \mathrm{~mm}$ \\
\hline$\alpha_{\mathrm{h}}$ & High-speed rotor angular ratio & $10 \%$ & $90 \%$ \\
\hline$\alpha_{1}$ & Low-speed rotor angular ratio & $10 \%$ & $90 \%$ \\
\hline$\alpha_{\mathrm{s}}$ & $\begin{array}{c}\text { Angular ratio of the } \\
\text { ferromagnetic pole pieces }\end{array}$ & $10 \%$ & $90 \%$ \\
\hline $\mathrm{h}_{\mathrm{h}}$ & $\begin{array}{l}\text { High-speed rotor rim } \\
\text { thickness }\end{array}$ & $30 \mathrm{~mm}$ & $200 \mathrm{~mm}$ \\
\hline $\mathrm{h}_{1}$ & $\begin{array}{c}\text { End bell thickness of the } \\
\text { low-speed rotor }\end{array}$ & $30 \mathrm{~mm}$ & $200 \mathrm{~mm}$ \\
\hline $\mathrm{h}_{\mathrm{s}}$ & $\begin{array}{l}\text { End bell thickness of the } \\
\text { ferromagnetic pole pieces }\end{array}$ & $30 \mathrm{~mm}$ & $200 \mathrm{~mm}$ \\
\hline $\mathrm{e}_{\mathrm{r}_{-}} \mathrm{h}$ & $\begin{array}{l}\text { High-speed rotor rim } \\
\text { thickness }\end{array}$ & $30 \mathrm{~mm}$ & $200 \mathrm{~mm}$ \\
\hline $\mathrm{e}_{\mathrm{r}_{-} 1}$ & $\begin{array}{l}\text { Thickness of the high-speed } \\
\text { rotor yoke reinforcement }\end{array}$ & $30 \mathrm{~mm}$ & $200 \mathrm{~mm}$ \\
\hline $\mathrm{l}_{\mathrm{h}}$ & $\begin{array}{l}\text { Length of the high-speed rotor } \\
\text { yoke reinforcement }\end{array}$ & $0.1 * L_{\text {magn }}$ & $0.9^{*} \mathrm{~L}_{\text {magn }}$ \\
\hline
\end{tabular}

where $\mathrm{L}_{\text {magn }}$ is the length of the magnetic part determined after the magnetic finite element analysis (see below).

\section{Optimization procedure}

Figure 9 describes the mono-objective optimization procedure. To begin, an initial set of parameters was computed, in addition to conducting the magnetic finite element analysis described above. This analysis provided the magnetic radial force and magnetic part length, which depended on the maximum gear torque per meter. Next, the magnetic part length was assumed to have the maximum gear torque presented in Table 2. The mechanical finite element analysis described above could then be performed. The objective function and mechanical constraints were evaluated for this parameter pair.

To complete this optimization procedure, a Particle Swarm Optimization (PSO) algorithm was employed, as described in [12] and [16]. PSO is a stochastic search and optimization algorithm, in which the trajectory of each particle (parameter) is adjusted towards its own best position, and the overall best position is calculated using neighbors as well as the whole swarm [17]. This algorithm then chooses different parameter sets in order to minimize the objective function until the maximum iteration number has been reached. The optimal solution minimizes the objective function while respecting the mechanical constraints.

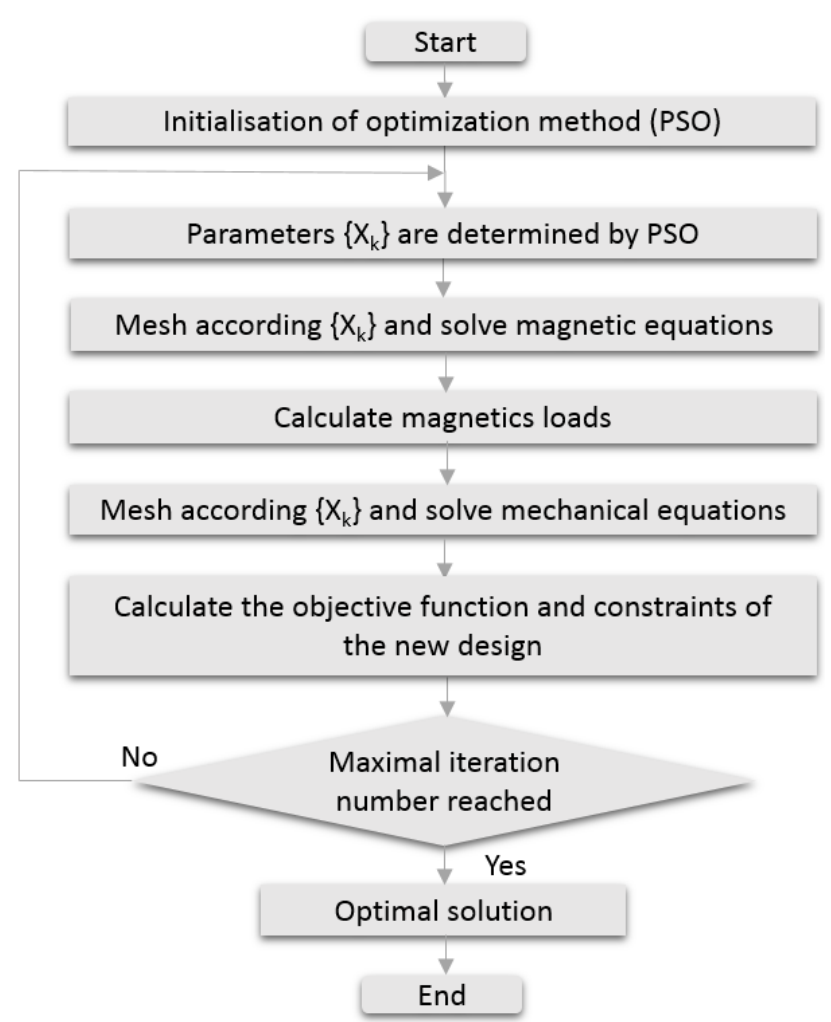

Fig. 9 Procedure of the optimization algorithm with the PSO (Particle Swarm Optimization) method

\section{RESULTS}

Figure 10 displays the magnetic finite element analysis for an optimal solution that minimizes material costs. Figures 11-13 depict the mechanical finite element analysis for the magnetic torque and radial magnetic force when evaluating the various mechanical constraints for an optimal solution of these structural parts. 


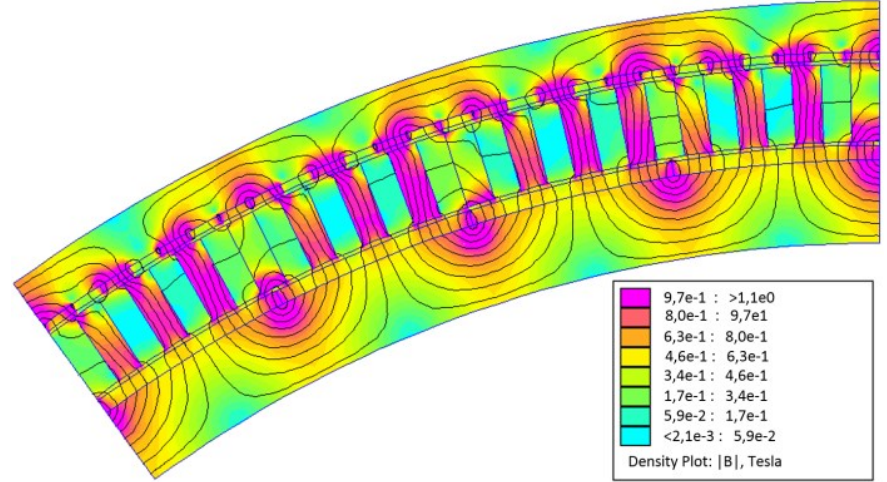

Fig. 10: Flux density in the magnetic parts of the magnetic gear, as part of the magnetostatic analysis
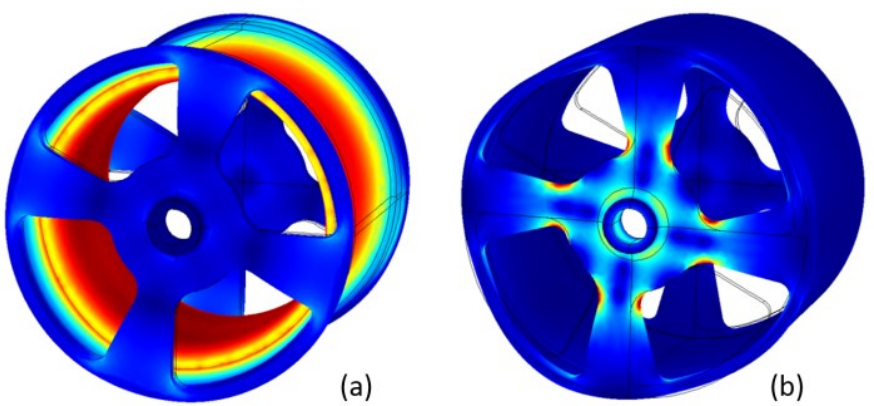

Fig. 11: Von Mises stress in the structural part for a stationary analysis of the low-speed rotor with (a) radial magnetic force (b) magnetic torque
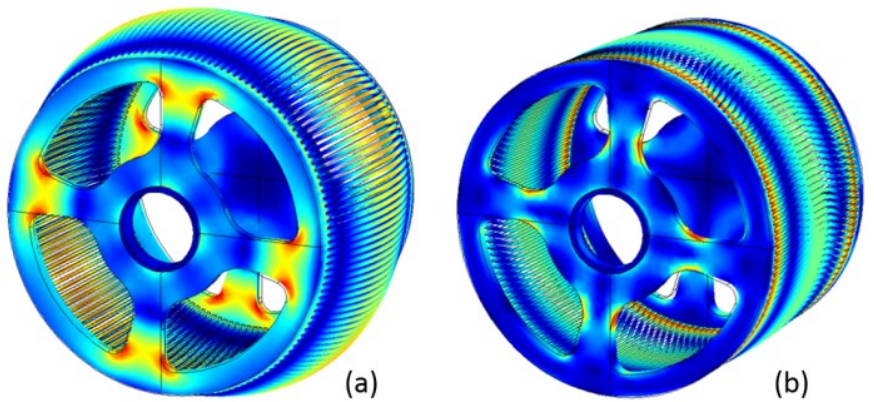

(b)

Fig. 12: Von Mises stress of the structural part for a stationary analysis of the fixed ferromagnetic pole pieces with (a) radial magnetic force (b) magnetic torque
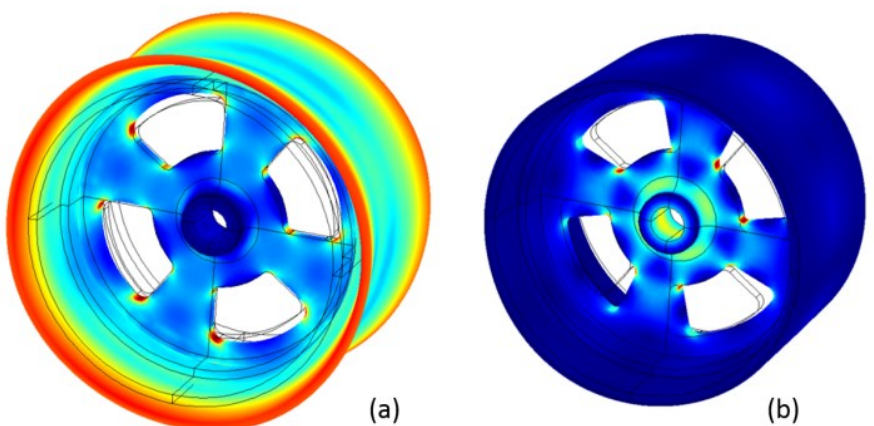

Fig. 13: Von Mises stress of the structural part for a stationary analysis of the high-speed rotor with (a) radial magnetic force (b) magnetic torque
Table 4 lists, for an optimal solution, the mass, material costs and torque density of the magnetic gear. It can be observed that the three structural parts account for $42.2 \%$ of the total mass yet only $7.1 \%$ of the total material costs. Moreover, low-speed rotor masses and material costs are the largest component among the three structural parts. Permanent magnets only represented $6.7 \%$ of total mass, but $75.6 \%$ of total material costs due to the expense of permanent magnets. Magneto-mechanical parts make up a significant portion of the total mass $(51 \%)$ and total material costs $(17.3 \%)$.

TABLE 4: MASS, MATERIAL COST AND TORQUE DENSITY IN THE OPTIMAL SOLUTION FOR THE VARIOUS MAGNETIC GEAR PARTS

\begin{tabular}{|c|c|c|c|c|c|}
\hline \multirow{2}{*}{} & \multicolumn{2}{|c|}{ Mass } & \multicolumn{2}{c|}{ Material cost } & $\begin{array}{c}\text { Torque } \\
\text { density }\end{array}$ \\
\cline { 2 - 6 } & $1 \mathrm{e}^{3} \mathrm{~kg}$ & $\%$ & $\mathrm{k} €$ & $\%$ & $\mathrm{kNm} / \mathrm{m}^{3}$ \\
\hline Magnetic parts & $\mathbf{5 . 5}$ & $\mathbf{6 . 7}$ & $\mathbf{3 6 3}$ & $\mathbf{7 5 . 6}$ & - \\
\hline $\begin{array}{c}\text { Low-speed rotor } \\
\text { permanent magnets }\end{array}$ & 2.0 & 2.5 & 132 & 27.5 & \\
\hline $\begin{array}{c}\text { High-speed rotor } \\
\text { permanent magnets }\end{array}$ & 3.5 & 4.3 & 231 & 48.1 & \\
\hline $\begin{array}{c}\text { Magneto- } \\
\text { mechanical parts }\end{array}$ & $\mathbf{4 1 . 4}$ & $\mathbf{5 1 . 0}$ & $\mathbf{8 2 . 8}$ & $\mathbf{1 7 . 3}$ & - \\
\hline Low-speed rotor yoke & 13.7 & 16.9 & 27.4 & 5.7 & \\
\hline $\begin{array}{c}\text { Ferromagnetic pole } \\
\text { pieces }\end{array}$ & 8.0 & 9.9 & 16.0 & 3.3 & \\
\hline $\begin{array}{c}\text { High-speed rotor } \\
\text { yoke }\end{array}$ & 19.7 & 24.3 & 39.4 & 8.2 & \\
\hline Structural parts & $\mathbf{3 4 . 2}$ & $\mathbf{4 2 . 2}$ & $\mathbf{3 4 . 2}$ & $\mathbf{7 . 1}$ & - \\
\hline Low-speed rotor & 15.9 & 19.6 & 15.9 & 3.3 & - \\
\hline $\begin{array}{c}\text { Fixed ferromagnetic } \\
\text { poles pieces }\end{array}$ & 7.1 & 8.8 & 7.1 & 1.5 & - \\
\hline High-speed rotor & 11.2 & 13.8 & 11.2 & 2.3 & - \\
\hline Total & $\mathbf{8 1 . 1}$ & $\mathbf{1 0 0}$ & $\mathbf{4 8 0}$ & $\mathbf{1 0 0}$ & $\mathbf{8 6 . 5}$ \\
\hline
\end{tabular}

\section{CONCLUSION}

This paper has described a novel approach to the overall design and optimization of magnetic gears (magnetic parts and structural parts); it has taken into account both the arrangement and mechanical (deformation and stress) constraints for wind turbine applications.

It can be concluded that:

1) The magneto-mechanical and structural parts of magnetic gears exert a significant impact on both total mass and total material costs. The results obtained have validated this novel approach to the overall design and optimization of magnetic gears, including magnetic and structural parts. 
2) For the fixed ferromagnetic pole pieces in particular, optimization results reveal the necessity to take into account mechanical constraints. The radial deflection constraint due to radial magnetic force yields a radial thickness of ferromagnetic pole pieces much higher than the thickness computed using a simple magnetic optimization.

3) The optimal solution depends strongly on the geometry and parameterization of the three structural parts. It would be helpful to carry out the same optimization procedure with another structural part geometry in order to compare results.

4) The optimal solution is obtained with a fixed external diameter of the magnetic parts equal to $3.8 \mathrm{~m}$. This diameter however is quite likely too small for a 2.5$\mathrm{MNm}$ nominal torque. It would be beneficial to carry out the same optimization with a larger external diameter so as to increase the diameter-to-length ratio of the magnetic gear and thereby lower the material costs.

5) The computation time of the present optimization procedure is rather long (more than 1 day with an Intel Xeon E5-1630 v3, 8 threads, $3.70 \mathrm{GHz}$, parallel computation) since the procedure entails a $2 \mathrm{D}$ magnetic finite element analysis and six 3D mechanical finite element analyses.

To improve the design and optimization of magnetic gears, the present approach should be adapted by introducing a larger-scale optimization that takes into account larger part sizes for the indirect magnetic drive presented in Figure 1.c (for instance, by including magnetic gears and a high-speed generator). It would also be worthwhile to replace the finite element analysis by an analytical expression to reduce computation time.

\section{ACKNOWLEDGMENTS}

The authors would like to thank the Jeumont Electric company for the wide range of discussions held on the topic of wind turbine design and, more specifically, $D$. Laloy, A. Fasquelle and D. Ekeom.

\section{REFERENCES}

[1] F. Spinato, P. Tavner, G. Van Bussel, Reliability of wind turbine subassemblies, IET Renewable Power Generation, Vol. 3, Iss.4, 2009

[2] K. Atallah, and D. Howe, A novel high-performance magnetic gear, IEEE Trans. Magn., vol. 37, No. 4, pp. 2844-2846, July 2001

[3] K. Atallah, S.D. Calverley, D. Howe, Design, Analysis and realization of a high-performance magnetic gear, IEEE Proc.Electr. Power Appl., Vol. 151, No. 2, March 2004

[4] P. O. Rasmussen, T. O. Andersen, F. T. Jorgensen, and O. Nielsen, Development of a high-performance magnetic gear, IEEE Trans. Ind. Appl, vol. 41, No. 3, pp. 764-770, May/Jun. 2005.

[5] T. Lubin, S. Mezani, A. Rezzoug, Analytical computation of magnetic field distribution in a magnetic gear, IEEE Trans. on magnetics, Vol. 46, No. 7, July 2010

[6] E. Gouda, S. Mezani, L. Baghli, A. Rezzoug, Comparative study between mechanical and magnetic planetary gears, IEEE Trans. on magnetics, Vol. 46, No. 2, Feb 2011

[7] L. N. Jian, K. T. Chau, D. Zhang, J. Z. Jiang, and Z. Wang, $A$ magnetic geared outer-rotor permanent-magnet brushless machine for wind power generation, IEEE 42nd IAS Annual Meeting Ind. Appl., Sep. 23-27, 2007, pp. 573-580

[8] N. W. Frank and H. A. Toliyat, Gearing ratios of a magnetic gear for wind turbines, in Proc. IEEE Int. Elect. Mach. Drives Conf. (IEMDC), May 3-6, 2009, pp. 1224-1230.

[9] D. Matt, J. Jac, N. Ziegler, Design of a Mean Power Wind Conversion Chain with a Magnetic Speed Multiplier, Advances in Wind Power, Chap 10, INTECH, November 2012

[10] A. Penzkofer, K. Atallah, Magnetic Gears for High Torque Applications, IEEE Trans. on magnetics, Vol. 50, No. 11, November 2014

[11] L. Jing, L. Liu, M. Xiong and D. Feng, Parameters Analysis and Optimization Design for a Concentric Magnetic Gear Based on Sinusoidal Magnetizations, IEEE Trans. on appl. Supercond., Vol. 24, No. 5, 2014

[12] S. Niu, N. Chen, S. L. Ho and W. N. Fu, Design optimization of magnetic gears using mesh adjustable finite-element algorithm for improved torque, IEEE Trans. on magnetics, Vol. 48, No. 11, November 2012

[13] M.A. Mueller, A.S. McDonald, D.E. MacPherson, Structural mass in direct drive permanent magnet electrical generator, IET Renewable Power Generation, Vol.2, No. 1, pp 3-15, 2008

[14] J. Lemaitre, J-L. Chaboche, A. Benallal, R. Desmorat, Mécanique des matériaux solides, 3rd edition, Dunod, 2009.

[15] A. Zavvos, A.S. McDonald, M. Mueller, Structural optimization tools for iron cored permanent magnet generators for large direct drive wind turbines, IET Conference RPG 2011

[16] J. Aubry, H. BenAhmed, B. Multon, Sizing optimization methodology of a surface permanent magnet machine-converter system over a torque-speed operating profile: Application to a wave energy converter, IEEE Trans. on Indus Electronics, Vol. 59, No. 5, 2012

[17] S. L. Ho, S. Yang, G. Ni, and H. C. Wong, A particle swarm optimization method with enhanced global search ability for design optimizations of electromagnetic devices, IEEE Trans. on magnetics, Vol. 42, No. 4, 2006 